\title{
0 discurso do Senhor, Deus de Israel, em Ex 34,6c-7d: análise poética e/ou linguístico-literária do texto hebraico
}

\author{
The Speech of the LoRD God of Israel in Ex 34: 6c-7d: \\ Poetic and/or Linguistic-Literary Analysis of the \\ Hebrew Text
}

\section{El discurso del Señor Dios de Israel em Ex 34,6c-7d: análisis poético y/o lingüístico-literario del texto hebreo}

\author{
Matthias Grenzer* \\ Luciano José Dias**
}

\begin{abstract}
RESUMO
Nas narrativas poéticas que pertencem ao Pentateuco, os discursos diretos tem grande destaque. Em geral, caracterizam-se por um emprego mais concentrado de elementos estilísticos, além de não apresentarem formas verbais que, em contrapartida, caracterizam a narração, onde se ouve ou lê a voz do narrador. Um dos discursos diretos mais marcantes no Pentateuco é a fala do Senhor, Deus de Israel, em Ex 34,6c-7d. O Artigo aqui apresentado se propõe a investigar a configuração poética e/ou linguístico-literária dessa microunidade da narrativa bíblica. Parte-se de um olhar para os sinais massoréticos que indicam pausas e junções no momento da leitura, seja em voz alta, seja em silêncio. Segue-se, com base na análise morfológico-sintática das palavras e na análise sintática delas em vista da construção das frases, a descrição da configuração artística do arranjo altamente retórico do discurso divino em Ex 34,6c-7d. Dessa forma, o exercício exegético aqui exposto revelará novamente o quanto as narrativas bíblicas, por serem literatura, ganham características de arte.

Palavras-chave: narrativa bíblica, discurso direto, análise poética.
\end{abstract}

\begin{abstract}
In poetic narratives that belong to the Pentateuch, the direct discourses have great prominence. In general, they are characterized by a more concentrated use of stylistic elements, besides not having verbal forms that, in contrast, characterize the narration, where one hears or reads the narrator's voice. One of the most striking direct discourses in the Pentateuch is the speech of the Lord, God of Israel, in Exodus 34: 6c-7d. The article presented here intends to investigate the poetic and/or linguistic-literary configuration of
\end{abstract}

* Doutor em Teologia pela Faculdade St. Georgen em Frankfurt, Alemanha. Mestre em História pela PUC-SP. Estágio de Pós-Doutorado em Teologia na PUC-Rio. Líder do Grupo de Pesquisa TIAT. E-mail: mgrenzer@pucsp.br

** Mestrando em Teologia na PUC-SP. Bacharel em Teologia pela Faculdade Metodista de São Paulo. Membro do Grupo de Pesquisa TIAT. E-mail: lucianojdias@gmail.com 
this microunity of the biblical narrative. One starts by looking at masoretic signs that indicate pauses and junctions at the time of reading, either out loud or in silence. Following, based on the morphological-syntactic analysis of words and the basis of their syntactic function in view of sentence construction, the description of the artistic configuration of the highly rhetorical arrangement of the divine discourse in Ex 34: 6c-7d. Thus, the exegetical exercise here exposed will again reveal how much biblical narratives, being literature, gain characteristics of art.

Keywords: biblical narrative, direct speech, poetic analysis.

\section{RESUMEN}

En las narraciones poéticas que pertenecen al Pentateuco, los discursos directos tienen gran importancia. En general, se caracterizan por un uso más concentrado de elementos estilísticos, además de no presentar formas verbales que, por otro lado, caracterizan la narración, donde uno escucha la voz del narrador. Uno de los discursos directos más llamativos en el Pentateuco es el discurso del SEÑor, Dios de Israel, en Éxodo 34,6c-7d. El artículo presentado aquí pretende investigar la configuración poética y/o lingüístico-literaria de esta microunidad de la narrativa bíblica. Uno comienza observando los signos masoréticos que indican pausas y uniones al momento de la lectura, ya sea en voz alta o en silencio. Sigue, sobre la base del análisis morfológico-sintáctico de las palabras y la base de su análisis sintáctico en vista de la construcción de oraciones, la descripción de la configuración artística del arreglo altamente retórico del discurso divino en Ex 34,6c-7d. Por lo tanto, el ejercicio exegético aquí expuesto nuevamente revelará cuánto las narraciones bíblicas, siendo literatura, adquieren características del arte.

Palabras clave: narrativa bíblica, discurso directo, análisis poética.

\section{Introdução}

Em meio às narrativas bíblicas, que são poesia épica, existem diferenças marcantes entre os trechos de narração, nos quais se ouve ou lê a voz do narrador, e os discursos diretos, nos quais o narrador empresta sua voz às personagens participantes da trama. Certas formas verbais e determinados tipos de frases, pois, somente ocorrem em discursos diretos (GRENZER, 2016, p. 15-32). Além disso, os discursos diretos são semelhantes aos poemas e/ou aos discursos poéticos, que pertencem a outro gênero literário encontrado na Bíblia Hebraica, a dizer, à poesia lírica. Lembra-se também que "o conteúdo do discurso direto está estreitamente ligado à função dele: a) expressar emoções, b) acordar posturas, c) motivar alguém a agir ou d) transmitir informação" (BAR-EFRAT, 2006, p. 81).

Dentro da macronarrativa sobre o êxodo, alguns discursos diretos do SENhor, Deus de Israel, adquirem importância ímpar. Em especial, ganham destaque aquelas falas em que Deus se refere a seu nome, insistindo em sua presença e em sua disposição de relacionar-se com seu povo. Nesse sentido, Ex 34,6c-7d chama a atenção do ouvinte-leitor.

A descrição mais exata da configuração poética do que se ouve ou lê em Ex 34,6c-7d é o exercício apresentado neste Artigo. Buscam-se respostas às seguintes questões: Como os sete elementos do discurso divino em 
questão se encontram agrupados linguisticamente? Onde estão as subdivisões das pausas na leitura e/ou na proclamação dos versetos? Quais são os elementos estilísticos empregados na construção desse discurso direto, o qual tem a configuração de um poema lírico? Não se pretende neste Artigo chegar a um estudo histórico-teológico do que se ouve ou lê em Ex 34,6c-7d. Contudo, tem-se consciência de que a forma linguístico-literária e/ou configuração poética de um texto que se apresenta como literatura aproxima o ouvinte-leitor ao sentido do que este ouve ou lê.

\section{“O Senhor é o Senhor" (v. 6c)}

Antes de analisar cada verseto, será apresentado todo o discurso direto presente em Ex 34,6c-7d, inclusive a introdução dele em Ex 34,6a-b. Segue-se em relação ao texto hebraico o que se lê na edição crítica da Biblia Hebraica Stuttgartensia (ELLIGER; RUDOLPH, 1997), inclusive com atenção aos acentos massoréticos, a fim de acompanhar como essa tradição judaica pertencente à Idade Média propõe juntar ou separar as palavras, indicando a entonação de cada uma delas e, dessa forma, a melodia da leitura, sendo que, assim, em certos momentos ocorre a determinação das relações sintáticas entre os elementos que compõem as frases (FRANCISCO, 2008, p. 202-213; TOV, 1997, p. 54-58). Para facilitar a compreensão das análises que se seguem, o texto bíblico é apresentado aqui de forma segmentada.

\begin{tabular}{|c|c|c|}
\hline 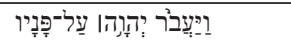 & V. $6 \mathrm{a}$ & O SEnHOR passou diante da face dele \\
\hline 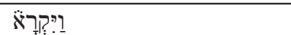 & v. $6 b$ & e proclamou: \\
\hline 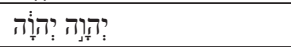 & V. $6 \mathrm{c}$ & O SENHOR é O SENHOR, \\
\hline 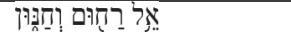 & V. 6d & um Deus compassivo e misericordioso, \\
\hline 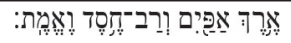 & V. 6 e & longânime e abundante em lealdade e fidelidade, \\
\hline 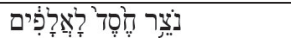 & v. $7 \mathrm{a}$ & guardador de lealdade a milhares, \\
\hline 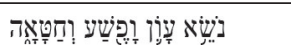 & V. $7 \mathrm{~b}$ & carregador de culpa, rebeldia e pecado; \\
\hline 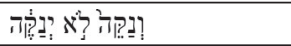 & V. $7 \mathrm{c}$ & mas, inocentar, não inocenta, \\
\hline 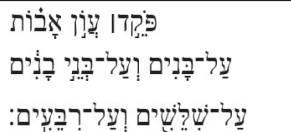 & $\begin{array}{l}\text { v. } 7 d \alpha \\
\text { v. } 7 d \beta \\
\text { v. } 7 d \gamma\end{array}$ & $\begin{array}{l}\text { preocupado com a culpa de pais } \\
\text { junto a filhos e junto a filhos de filhos, } \\
\text { junto à terceira e junto à quarta (geração). }\end{array}$ \\
\hline
\end{tabular}

Acompanhando somente os acentos disjuntivos, os massoretas indicam, através do sillûq, a maior pausa no final do v. 6. A segunda maior pausa, o 'atnah , figura debaixo da palavra traduzida como "misericordioso" (v. 6d), sendo que o versículo se divide aqui em duas metades. Enquanto 
esses dois acentos formam as duas pausas maiores do grupo dos acentos chamados de "imperadores", outros acentos do grupo dos "reis" indicam pausas um pouco menores (TOV, 1997, p. 56). Nesse sentido, observa-se o zarq $\bar{a}$ ' junto à expressão "diante da face dele" (v. 6a), o səğ $\hat{o} l \partial t \bar{a}$ ' junto ao termo "e proclamou" (v. 6b), o zāqē $q \bar{p}$ ațān com o segundo tetragrama (v. 6c) e o tipphāa junto às palavras "compassivo" (v. 6d) e "longânime" (v. 6e), sendo que esta última, em hebraico, é formada por dois termos, que também poderiam ser traduzidos como "lento na ira".

Em vista da dupla presença do tetragrama no v. 6c, por sua vez, é importante observar que os massoretas não optaram por indicar uma pausa entre as duas presenças do nome de Deus. Pelo contrário, um acento conjuntivo - ver o munnah embaixo do primeiro tetragrama no v. $6 \mathrm{c}-$ favorece justamente a junção dos dois tetragramas, sem que se interrompa a melodia da leitura. Mais ainda, "a pontuação massorética separa o termo 'e proclamou' no v. $6 \mathrm{~b}$ dos dois tetragramas no v. $6 \mathrm{c}$, optando, assim, por um início do discurso direto com a dupla presença do nome de Deus" (SCORALICK, 2002, p. 78).

Como, no entanto, pode ser compreendida a sintaxe de Ex 34,6c? Quais as funções que pertencem às palavras em vista da construção da frase, seguindo-se a subdivisão aqui proposta? A repetição do tetragrama, muitas vezes, é compreendida como ênfase, semelhante à presença dupla de outros nomes em alguns lugares (ver “Abraão" em Gn 22,11, “Jacó” em Gn 46,2, "Moisés" em Ex 3,4 e "Samuel" em 1Sm 3,11). Afirma-se que "o staccato na linguagem sublinharia a dramaticidade do momento" (FRANZ, 2003, p. 165). Nesse sentido, o que se segue ao v. 6c seria atributivo, em forma de aposição - "O SENHOR, o SENHOR, um Deus compassivo e misericordioso, longânime e abundante em lealdade e fidelidade" (v. 6c-e) - ou de predicativo - "O Senhor, o Senhor é um Deus compassivo e misericordioso, longânime e abundante em lealdade e fidelidade" (v. 6c-e). No primeiro caso, não se teria uma frase completa, mas um substantivo seguido por uma lista de atributos. No segundo caso, se leria uma frase nominal, na qual os dois tetragramas no v. $6 \mathrm{c}$ formariam o sujeito, e o que se lê a partir do v. $6 \mathrm{~d}$, o predicado do sujeito. Contudo, esse tipo de ênfase parece não se encaixar bem, porque quem discursa - ver "O SENHOR" no v. 6a - pronuncia seu próprio nome (SCORALICK, 2002, p. 41). Quer dizer, o locutor não se dirige a outro para, de forma reforçada, chamar a atenção dele.

Existe, no entanto, ainda outra forma de compreender o início do discurso direto de Deus em Ex 34,6c, sendo que esta é a defendida por este Artigo. Os dois tetragramas, pois, podem formar uma frase nominal com 
sujeito e predicado do sujeito, sendo que o segundo elemento é seguido por atributos em forma de aposição: "O SENHOr é o SENHOR, um Deus compassivo e misericordioso, longânime e abundante em lealdade e fidelidade" (v. 6c-e). Nesse caso, o Senhor, Deus de Israel, também insiste enfaticamente em seu nome. Contudo, não no sentido de chamar sua própria atenção, mas, aparentemente, para destacar a diferença entre seu nome - inclusive aquilo que tal nome representa e que é explicitado novamente nos atributos que se seguem - e os nomes pertencentes a outros deuses (cf., em vista dessa compreensão do v. 6c, GRENZER; DIAS, 2018).

\section{"Um Deus compassivo e misericordioso" (v. 6d)}

Observem-se novamente os sinais de pausa, que se encontram embaixo ou em cima das palavras hebraicas. Como descrito antes, por meio de um $z \bar{a} q \bar{e} \bar{p} q \bar{a} t \bar{a} n$ em cima da terceira consoante da segunda presença do nome de Deus no v. 6c (יהi), é indicada uma pausa menor. Assim, o ouvinte-leitor percebe que, no início do v. 6d, se inicia outra unidade da frase.

Essa segunda parte da frase, que continua a trazer o discurso direto do SENHOR em Ex 34,6c-7d, é formada por três palavras (v. 6d). Levando em conta os acentos massoréticos, o 'atnah embaixo da palavra traduzida

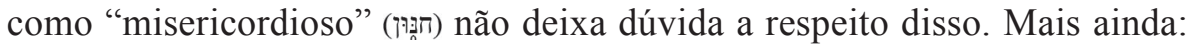
trata-se da segunda maior pausa possível, sendo que, entre os acentos separadores ou distinctivi, justamente o 'ațnah adquire a função de dividir uma frase em duas partes.

No mais, podem ser observados no v. $6 \mathrm{~d}$ ainda dois acentos servos, pertencentes à classe dos acentos conjuntivos. $\mathrm{O}$ primeiro deles, chamado de $m \bar{e} r \underline{k} a$, está debaixo da palavra traduzida como "Deus" (ֵֵֵ) e é aberto para o lado esquerdo. Indica-se com isso que tal palavra deve ser juntada à próxima. $\mathrm{O}$ segundo acento servo, chamado de tippḥa ', está debaixo da palavra traduzida como "compassivo" (ㄱำ) e é aberto para o lado direito, o que sinaliza que tal palavra deve ser juntada à palavra anterior. Assim, as duas palavras hebraicas em questão formam um conjunto: "um Deus

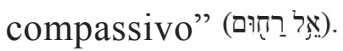

Em seguida, a formulação hebraica no v. 6d trabalha com a conjunção traduzida como "e" (?). Como conjunção, tal palavra, a partir de seu valor semântico, é estruturante. Funciona semelhantemente a um acento conjuntivo. Ou seja, com o emprego da conjunção, o ouvinte-leitor compreende a sequência das afirmações no discurso direto em Ex 34,6c-7d: primeiramente, o SENHOR diz que ele é "um Deus compassivo" (v. 6d $\alpha$ ); 
em seguida, ele junta a essa ideia outra afirmação: ou seja, além de "compassivo", ele também é "misericordioso" (v. 6d $\beta$ ).

Quer dizer, pelo que é indicado por meio dos sinais de pausa e da conjunção, as três palavras no v. $6 \mathrm{~d}$ devem ganhar o seguinte ritmo ao serem lidas e pronunciadas: o substantivo, na primeira posição, é qualificado pelo primeiro adjetivo, que ocupa a segunda posição. Aqui está uma primeira ideia. Em seguida, o substantivo já conhecido é qualificado uma segunda vez, justamente pelo segundo adjetivo, que ocupa a terceira posição. Com isso, a primeira reflexão é ampliada por uma segunda. Percebe-se com isso também que a configuração sintática da frase apoia a impressão de que o v. $6 \mathrm{~d}$ ganhe certa autonomia como verseto.

Dito com outras palavras, observa-se o seguinte: o v. 6d começa com a palavra "Deus" (אל), um substantivo masculino singular que é apresentado na forma do absoluto. Seguem-se dois adjetivos atributivos como duas aposições, sendo que estes se encontram interligados por uma conjunção: "compassivo e misericordioso" (רחוּם וְחַוּן). No caso, os adjetivos, como aposições, determinam o substantivo, justamente por apresentarem qualidades em relação a este último. Há congruência entre o substantivo e os dois adjetivos, sendo que as três palavras aparecem na forma do masculino singular absoluto. Mais ainda, de acordo com o que ocorre comumente, os dois adjetivos seguem, como aposições, o substantivo ao qual se referem. Assim, não há dúvida sobre as referências estabelecidas.

Contudo, é preciso levar em consideração que o que se ouve ou lê no v. 6d ("um Deus compassivo e misericordioso") não forma uma frase completa, ao contrário do que se encontra no v. 6c ("O Senhor é o Senhor"), onde se pode detectar uma frase nominal. Pelo contrário, o v. $6 \mathrm{~d}$ traz apenas um elemento atributivo, o qual, com certa autonomia, é configurado por três palavras. Além disso, com o que se ouve ou se lê no v. $6 \mathrm{~d}$ inicia-se uma lista formada por sete elementos atributivos (6d.e.f.7a.b.c.d). Nenhum desses elementos, por si só, forma uma frase completa, mas, a partir de tais elementos, nasce uma lista de tópicos, sendo que cada tópico atribui uma qualidade ou um conjunto de qualidades ao Senhor que se diz SEnhor (v. 6c), sendo ele o único ponto de referência para todos os atributos.

\section{“Longânime e abundante em lealdade e fidelidade" (v. 6e)}

Outra vez se encontram abaixo das consoantes do v. 6e os sinais pertencentes à classe dos acentos conjuntivos chamados de mērḱ e tippḥa $\bar{a}$, exatamente embaixo das duas palavras traduzidas como "longânime", sendo 
que também poderiam ser traduzidas, de forma mais literal ainda, como "lento para a ira", "de fôlego extenso" ou "com alongamento de narinas"

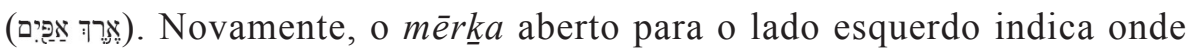
se inicia a sequência de palavras que formam uma expressão. O țippḥa ${ }^{\prime}$ aberto para o lado direito, por sua vez, indica o momento em que termina a expressão formada por várias palavras.

O mesmo fenômeno ocorre uma segunda vez no v. 6e. Outro mērka aberto para o lado esquerdo indica o início de mais uma sequência de palavras que formam uma só expressão, no sentido de uma unidade de pensamento ou algo que deve ser juntado durante a reflexão sobre o que é dito: ver o sinal debaixo da palavra traduzida como "lealdade" (תֶָ). Contudo, desta vez não se encontra um tippḥa $\bar{a}$ ' aberto para o lado direito, que indicaria o fim da unidade. Uma vez, pois, que um sof pasuq embaixo da palavra traduzida como "fidelidade" (אמֵֵֶ), em conexão com um sillûq, assinala o fim do versículo, não há mais a necessidade de indicar o fim da sequência da expressão por outro tippḥa

Com isso, percebe-se como os acentos colocados pelos massoretas indicam que o ouvinte-leitor deve juntar, primeiramente, as duas palavras

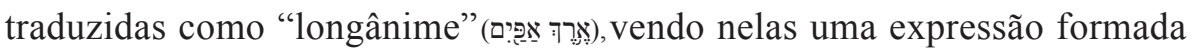
por dois vocábulos, a saber, por um adjetivo seguido por um substantivo. Logo em seguida, a formulação hebraica trabalha com a conjunção "e" (!). Como dito acima, trata-se de uma palavra escrita e pronunciada, que funciona como conjunção coordenativa. Nesse caso, a conjunção em questão introduz o segundo elemento na sequência do que é dito no v. 6c, sendo que este está no mesmo nível que o primeiro. Ou seja, de um lado, o Senhor, Deus de Israel, é pensado como "longânime" (v. 6e $\alpha$ ) e, do outro, ele é visto como "abundante em lealdade e fidelidade" (v. 6e $\beta$ ).

Contudo, o que se ouve ou se lê no v. 6 e $\beta$ encontra-se ainda mais subdividido. Percebe-se, primeiramente, a presença do adjetivo traduzido como "abundante" (ㄱ). Tal adjetivo, por sua vez, recebe dois complementos, formados por substantivos novamente conectados pela conjunção "e" (१). No entanto, essa conjunção funciona agora em um nível inferior à presença da mesma conjunção usada anteriormente. Enfim, compreende-se no v. 6e $\beta$ que "o Senhor é abundante em lealdade e fidelidade". No mais, em vista de todo o verseto $6 \mathrm{e}$, percebe-se uma estrutura paralela. A primeira expressão é formada por um adjetivo seguido de um substantivo e a segunda expressão, por um adjetivo seguido por dois substantivos. Com isso, tem-se a impressão de um movimento crescente.

Enfim, nos versetos lidos até agora (v. 6c-e) não apareceu nenhum verbo. O discurso direto do SENHOR em Ex 34,6c-7d começa com uma frase 
nominal (v. 6c), que é seguida por dois complementos (v. 6d-e), sendo que tais aposições são compostas somente por adjetivos, substantivos e conjunções. Além disso, observa-se que, em tamanho ou número de palavras, os versetos aumentam. Há a seguinte sequência: duas palavras (v. 6c), três palavras (v. 6d) e cinco palavras (v. 6e). Ou seja, o v. 6e não apenas fala da "longanimidade" e/ou "abundância" do SEnHor, Deus de Israel, mas, poeticamente, por ser composto por um número maior de palavras, ele também é o verseto mais longo até agora. Parece que, no nível da linguagem, ocorre algo capaz de apoiar pela forma o que, teologicamente, se torna o conteúdo da reflexão proposta.

Quer dizer, nos primeiros três versetos do discurso direto do Senhor em Ex 34,6c-7d, não é descrita nenhuma ação do Deus de Israel. Como já dito, não há verbos. Em contrapartida, as formulações poéticas insistem na descrição de características atribuídas ao SENHOR, sendo que estas, por meio da frase nominal (v. 6c) e da lista de elementos apresentados como aposições (v. 6d-7d), ganham a conotação de serem perenes ou eternas. Eis a tônica do discurso lírico em Ex 34,6c-7d.

\section{“Guardador de lealdade a milhares" (v. 7a)}

A formulação no v. 7a inicia-se com um particípio ativo na forma do singular masculino absoluto. Somente isso já chama a atenção do ouvinte-leitor do discurso direto do Senhor em Ex 34,6c-7d. Trata-se, pois, da primeira forma verbal usada. Até agora apenas substantivos, adjetivos e conjunções tinham aparecido. No entanto, o particípio ativo, para o qual não existe uma forma diretamente equivalente na língua portuguesa, não é um verbo finito, no sentido de ser um verbo conjugado ou flexionado. Pelo contrário, o particípio é um verbo substantivado, sendo que suas dimensões temporais não se encontram definidas. Nesse sentido, a expressão verbal no v. 7a, em princípio, afirma que o SENHOR é aquele que sempre "guardou", "guarda" e "guardará" sua "lealdade a milhares".

O particípio em questão pede, por sua vez, um complemento. Assim, sem ser usada a partícula que, na frase hebraica, comumente introduz o objeto direto, o particípio ativo traduzido como "guardador" é seguido pelo vocábulo "lealdade" ()ֶָ). Compreende-se, portanto, que o SENHOR, por meio de seu discurso direto, se autodescreve como "quem guarda a lealdade" (v. 7a). Aliás, surge com a presença do vocábulo "lealdade" a primeira repetição e, com isso, um paralelismo chamativo no discurso aqui estudado, uma vez que o mesmo substantivo já apareceu no verseto anterior (ver חֶֶ no v. 6e). 
Falta ainda outro complemento em forma de um objeto indireto, uma vez que a expressão "guardador de a lealdade" suscita diretamente a questão a respeito do direcionamento de tal ação divina. Assim aparece, no texto hebraico de Ex 34,6c-7d, a primeira preposição, sendo que esta introduz o primeiro numeral. Ou seja, ouve-se ou lê-se o objeto indireto "a

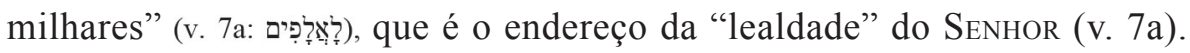

Finalmente, o verseto no v. 7 a ocupa, em meio aos sete versetos que formam o discurso direto do SENHOR em Ex 34,6c-7d, justamente a posição central. Três versetos (v. 6c-e), pois, antecedem o que se ouve ou se lê no v. $7 \mathrm{a}$, e outros três versetos (v. $7 \mathrm{~b}$-d) seguem o que se ouve ou se lê no v. 7a., sendo que tal centralidade, em princípio, é mais facilmente percebida e valorizada por quem ouve ou lê o texto em hebraico. Em todo caso, o que assume destaque por meio da forma e, com isso, através da configuração poética dada ao texto, também ganha realce quanto à reflexão teológica promovida pelas palavras artisticamente compostas. Afinal, vale o seguinte princípio para a poesia hebraica: o que deve ganhar centralidade no pensamento, em geral, ocupa o centro na composição literária.

\section{"Carregador de culpa, rebeldia e pecado" (v. 7b)}

Nota-se que os sinais massoréticos continuam a manter a melodia poética do discurso poético, ditando com maestria a entonação e as pausas pertinentes à sua harmonia. Quatro acentos condicionam a melodia e a entonação da leitura: o mērk $a$, um acento servo, pertencente à classe dos acentos conjuntivos, também conhecido como alongador, embaixo das pa-

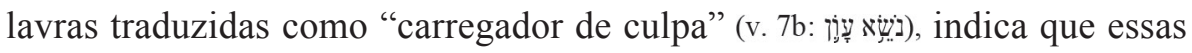
palavras devem ser lidas sem separação; o țippḥa ', divisor de unidade,

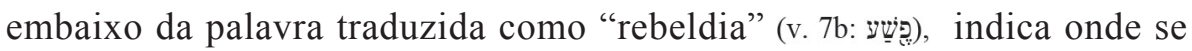
deve fazer uma breve pausa na leitura; o acento 'atnah h, principal acento divisor entre os versetos $7 \mathrm{~b}$ e $7 \mathrm{c}$, o qual está debaixo da palavra "pecado"

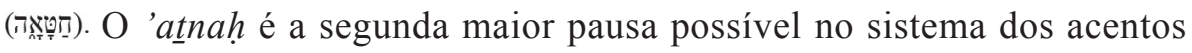
massoréticos, sendo que ele, entre os acentos separadores ou distinctivi, adquire a função de dividir um versículo em duas partes, propondo que se faça uma pausa maior neste momento.

Contudo, como o verseto anterior no v. $7 \mathrm{a}$, também o verseto no v. $7 \mathrm{~b}$ inicia-se com um particípio ativo singular masculino no grau verbal do Qal. Enquanto o SEnHor, Deus de Israel, estava sendo contemplado como "guardador" no v. 7a, agora, no início do v. 7b, ele é pensado como "quem carrega" ou "carregador". Com esse paralelismo, o qual surge a 
partir da forma verbal, garante-se a conexão e o fluxo do discurso. Mais ainda: o paralelismo é audível, sobretudo na língua hebraica. Existe, pois, uma pronúncia semelhante ou paronomásia entre a palavra traduzida como

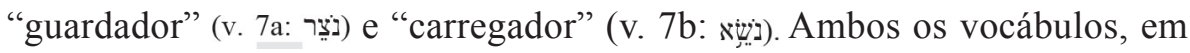
hebraico, começam com a letra nun, e as segundas letras, ao se ouvirem o tsade e o sin, são semelhantes na pronúncia.

O particípio no v. $7 \mathrm{~b}$, por sua vez, traz consigo três objetos diretos em forma de substantivos. Observa-se, com isso, uma cadeia de vocábulos, cuja carga semântica leva o pensamento do ouvinte-leitor na mesma direção: "culpa", "rebeldia" e "pecado" (v. 7b). Todos esses substantivos são empregados no singular e sem o uso do artigo definido, o que aumenta, outra vez, a intensidade do paralelismo. A conexão entre os vocábulos em questão é criada pelo duplo emprego da conjunção, traduzida aqui ora com vírgula, ora com a conjunção "e" (v. 7b).

No mais, com quatro palavras, ocorre, no v. $7 \mathrm{~b}$, novamente, um crescimento em relação ao volume do discurso divino. Após a sequência de duas (v. 6c), três (v. 6d) e quatro/cinco palavras (v. 6e), observa-se no v. 7a-b a sequência de três (v. 7a) para quatro palavras (v. 7b). Nesse sentido, os dois versetos no v. 7a-b, cujo paralelismo já foi apresentado acima, formam um conjunto composto justamente por sete palavras. Embora não se saiba mais exatamente qual seria a conotação simbólica do número sete, ninguém duvida do emprego desse número e de seus múltiplos como elementos estilísticos.

\section{"Mas, inocentar, não inocenta" (v. 7c)}

Após ter iniciado os dois versetos anteriores com particípios ativos ver o "guardador" (ניצר) no v. 7a e o "carregador" (ניצֵ) no v. 7b -, o discurso direto aqui estudado inicia o próximo verseto, após a conjunção agora compreendida como adversativa - ver a palavra "mas" (?) no início do v. $7 \mathrm{c}$-, com a forma verbal de um infinitivo absoluto, seguido pela negação e pelo mesmo verbo, agora flexionado no grau do Piel, na ação verbal da conjugação de prefixos (imperfeito), na terceira pessoa do singular masculino. Trata-se da chamada figura etimológica, sendo que esta traz o mesmo verbo duplamente, reforçando a forma flexionada pelo infinitivo absoluto. Não é possível traduzir tal construção de forma direta para o português, por faltarem formas verbais equivalentes. Contudo, a tradução aqui apresentada para o que se ouve ou se lê no texto hebraico procura

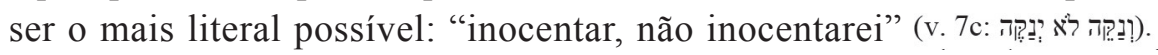


Tanto a repetição da mesma raiz verbal (נקה) em um espaço curtíssimo como a presença de um primeiro verbo finito, conjugado na flexão da conjugação de prefixos, chamam a atenção do ouvinte-leitor para o que é dito no v. 7c. Ao contrário, pois, de particípios e infinitivos, o verbo flexionado nas conjugações de sufixos e prefixos, assim como o imperativo, traz uma dimensão temporal consigo. No caso do v. 7c, a forma verbal remete o ouvinte-leitor ao futuro. Afirma-se que o SENHOR "não inocentará".

Também a primeira presença de uma partícula negativa é retoricamente chamativa. Até agora, pois, apenas foi dito quem é o SENHOR e como ele se comporta. Ou seja, recebeu destaque o que ele faz. Agora, no entanto, se diz o que ele "não" (לא (ל) faz ou "não" fará (v. 7c). Aliás, é a única vez que isso ocorre no discurso poético aqui investigado.

\section{"Preocupado com a culpa de pais junto a filhos e junto a filhos de filhos, junto à terceira e junto à quarta (geração)" (v.7d)}

Novamente merecem atenção os sinais massoréticos, sendo que estes, por excelência, indicam as pausas a serem guardadas na leitura do texto bíblico. Observa-se, logo após o verbo na primeira posição traduzido como "preocupado" (v. 7d: : sentido de "quem se preocupa" -, a presença do acento massorético chamado de lağarmêh. Este é a combinação dos acentos munnah, encontrado

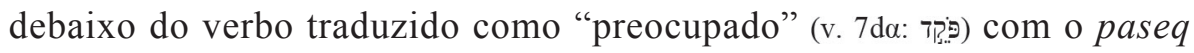
(I), o qual se encontra logo após o verbo, ou seja, no lado esquerdo. Tal acento, em geral, divide unidades que terminam com o acento revia", o qual pode ser verificado acima do substantivo traduzido como "pais"

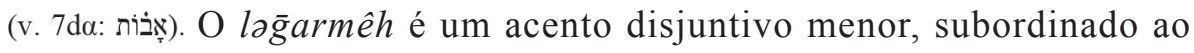
acento revia'. Ele pode ter outro servo junto à formulação do verseto. Neste caso, isso ocorre por meio de um segundo munnah, sendo que este

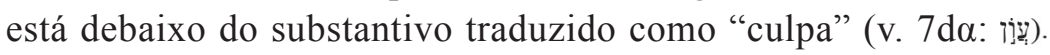

Aparecem ainda outros acentos massoréticos no v. $7 \mathrm{~d}$. Há uma sequência indicada por meio do munnah debaixo da palavra traduzida como "filhos de" (v. 7d $\mathrm{d}$ :

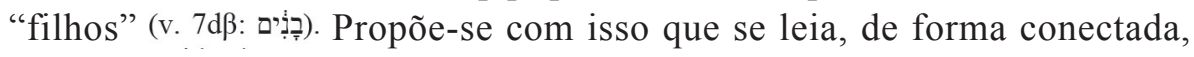

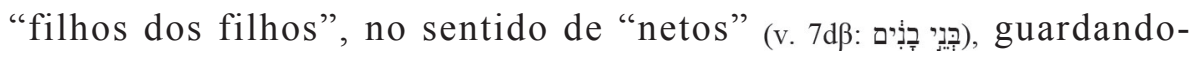
-se uma pequena pausa antes de seguir com a preposição traduzida como "junto a" (v. 7dy: לֶ). Avançando com a leitura, ainda se observa

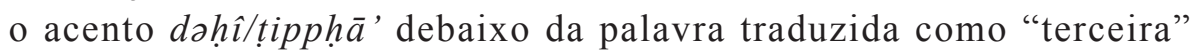

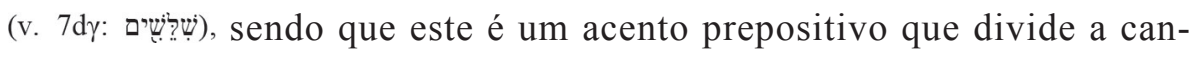


tilação. Propõe-se, portanto, outra pequena pausa antes de continuar a leitura até a conclusão do verseto.

Quanto à configuração poética e/ou linguístico-literária do v. $7 \mathrm{~d}$, o ouvinte-leitor, de forma imediata, percebe que se trata do verseto mais volumoso entre os sete versetos que formam o discurso direto do SENHOR, Deus de Israel, em Ex 34,6c-7d. Ao todo são doze palavras, número que pode guardar certa conotação simbólico-teológica. A formulação no v. $7 \mathrm{~d}$ inicia-se com um verbo apresentado na forma do particípio ativo, no singular masculino absoluto. Já é o terceiro particípio desse tipo no discurso aqui estudado: ver "quem guarda" ou "guardador" no v. 7a e "quem carrega" ou "carregador" no v. 7b. Como dito acima, tais particípios trazem consigo a ideia de uma ação constante, não limitada a determinado contexto cronológico. Nesse sentido, o SENHOR, Deus de Israel, se refere agora a si mesmo como "quem se preocupa" com algo, ou seja, como "quem visita" algo (v. 7d: פ⿴囗十). Quer dizer, ele sempre foi, é e será um "guardador" (v. 7a), um "carregador" (v. 7b) e alguém que está "preocupado" (v. 7d).

A carga semântica do vocábulo "preocupado com" (v. 7d), por sua vez, pede diretamente um ou vários complementos. Assim, segue-lhe um

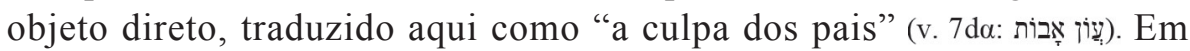
hebraico, não se exige um artigo definido na frente do segundo substantivo, o qual determinaria a definição de toda a expressão formada por dois substantivos. Quer dizer, compreende-se a seguinte ideia: "Quem se preocupa (com) uma culpa de pais" (v. $7 \mathrm{~d} \alpha$ ). No entanto, o português não se expressa dessa forma. Por mais que se insista em uma realidade vista como genérica, o artigo definido pode ser colocado. Ou seja, entende-se no v. $7 \mathrm{~d} \alpha$ que o SEnHor, Deus de Israel, em geral "se preocupa com a culpa dos pais". Ou, com outras palavras, junto às gerações futuras, quaisquer "culpas paternas" sempre são uma preocupação para Deus.

Após o objeto direto no v. 7d $\alpha$, o discurso do SENHOR, Deus de Israel, ainda introduz, por meio do uso quádruplo da preposição traduzida como "junto a" (v. 7d $\beta-\gamma$ : dicam, por meio da sequência em que são apresentados, um avanço quanto às gerações apresentadas: "filhos" (v. $7 \mathrm{~d} \beta$ ) - "filhos dos filhos", o que equivale aos "netos" (v. 7d $\beta$ ) - "terceiros", o que equivale aos "bisnetos" (v. 7d $\gamma$ ) - "quartos", o que equivale aos "trinetos" (v. $7 \mathrm{~d} \gamma$ ). São vocábulos próprios à língua hebraica, indicando-se as quatro gerações seguintes.

Enfim, o extenso conjunto de palavras no v. $7 \mathrm{~d} \alpha-\gamma$, apresentado aqui como uma sequência formada por um particípio ativo, por um objeto direto e por um quádruplo objeto indireto, traz, de modo magistral, o 
acorde final do discurso direto do Senhor, Deus de Israel, em Ex 34,6c$7 \mathrm{~d}$, chegando, assim, ao fim o longo período apositivo formado por seis versetos (v. 6d-7d).

\section{Considerações finais}

O estudo aqui apresentado procura elucidar a configuração poética do discurso direto atribuído ao Senhor, Deus de Israel, o qual se ouve ou se lê em Ex 34,6c-7d. De certa forma, também os escribas judeus chamados de massoretas se propuseram exatamente a isso, quando, na segunda metade do primeiro milênio, além de vocalizarem as palavras hebraicas grifadas somente com consoantes, colocaram seus sinais de pausa e de ausência de pausa no texto bíblico. No entanto, acolhendo o auxílio por parte dos sinais massoréticos e partindo de uma cuidadosa análise morfológico-sintática do que se ouve ou lê em Ex 34,6c-7d, descobre-se o emprego de alguns elementos estilísticos que conferem ao discurso direto do SEnHOR a sua configuração e, com isso, a sua beleza poética.

Em princípio, o discurso direto em Ex 34,6c-7d apresenta uma só frase. Trata-se de uma frase nominal que se ouve ou se lê no v. $6 \mathrm{c}-$ "O SEnhor é o Senhor" -, sendo que o predicativo do sujeito dela recebe, como aposições, sete expressões justapostas: "um Deus compassivo e misericordioso" (v. 6d), "longânime e abundante em lealdade e fidelidade" (v. 6e), "guardador de lealdade a milhares" (v. 7a), "carregador de culpa, rebeldia e pecado" (v. 7b), "inocentar, não inocenta" (v. 7c), "preocupado com a culpa de pais junto a filhos e junto a netos, junto à terceira e junto à quarta gerações" (v. 7d). No mais, as formulações das aposições empregam diversos elementos estilísticos: a ausência ampla do verbo flexionado nas conjugações de sufixos e prefixos - observa-se somente um verbo nessa condição, no v. 7c -; a presença multiplicada do particípio ativo (v. 7a.b.d $\alpha$ ) e da figura etimológica com uso do infinitivo absoluto (v. 7c); o acúmulo de substantivos e adjetivos, sendo que nascem paralelismos a partir de algumas repetições; uma oposição indicada pela conjunção com valor adversativo (v. 7b-c); a variação do tamanho das formulações dos versetos; o uso de números característicos - o discurso direto em Ex $34,6 \mathrm{c}-7 \mathrm{~d}$ é formado por justamente sete elementos, sendo que o último traz quatro elementos (v. 7d).

Juntando tais observações, descobre-se que o discurso direto do Senhor, Deus de Israel, em Ex 34,6c-7d, literariamente, é uma obra de arte. Como composição artisticamente elaborada, chama a atenção de seu 
ouvinte-leitor para o conteúdo veiculado pelas palavras. A demonstração, por sua vez, de como forma e conteúdo entram aqui em harmonia fica como tarefa para uma futura pesquisa.

\section{Referências bibliográficas}

BAR-EFRAT, Shimon. Wie die Bibel erzählt. Alttestamentliche Texte als literarische Kunstwerke verstehen. Gütersloh: Verlagshaus, 2006.

ELLIGER, Karl; RUDOLPH, Wilhelm. Biblia Hebraica Stuttgartensia. 5. ed. Stuttgart: Deutsche Bibelgesellschaft, 1997.

FRANCISCO, Edson de Faria. Manual da Bíblia Hebraica. Introdução ao texto massorético; guia introdutório para a Biblia Hebraica Stuttgartensia. 3. ed. São Paulo: Vida Nova, 2008.

FRANZ, Matthias. Der barmherzige und gnädige Gott. Die Gnadenrede vom Sinai (Exodus 34,6-7) und ihre Parallelen im Alten Testament und seiner Umwelt. Stuttgart: Kohlhammer, 2003.

GRENZER, Matthias. As dimensões temporais do verbo hebraico: desafio ao traduzir o Antigo Testamento. Pistis \& Praxis, Curitiba, v. 8, p. 15-32, 2016.

GRENZER, Matthias; DIAS, Luciano José. “O Senhor é o Senhor” (Ex 34,6c). Insistência no nome visando à relação. TeoLiterária, v. 8, n. 15, p. 140-153, 2018.

SCORALICK, Ruth. Gottes Güte und Gottes Zorn. Die Gottesprädikationen in Ex 34,6f und ihre intertextuellen Beziehungen zum Zwölfprophetenbuch. Freiburg: Herder, 2002.

TOV, Emanuel. Der Text der Hebräischen Bibel: handbuch der textkritik. Stuttgart:

Kohlhammer, 1997.

Submetido em: 31-8-2019

Aceito em: 22-10-2019 